Оригинальная статья/Original article

УДК 547-3:664.126

DOI: http://doi.org/10.20914/2310-1202-2018-2-200-205

Анализ красящих веществ желтых сахаров свеклосахарного производства

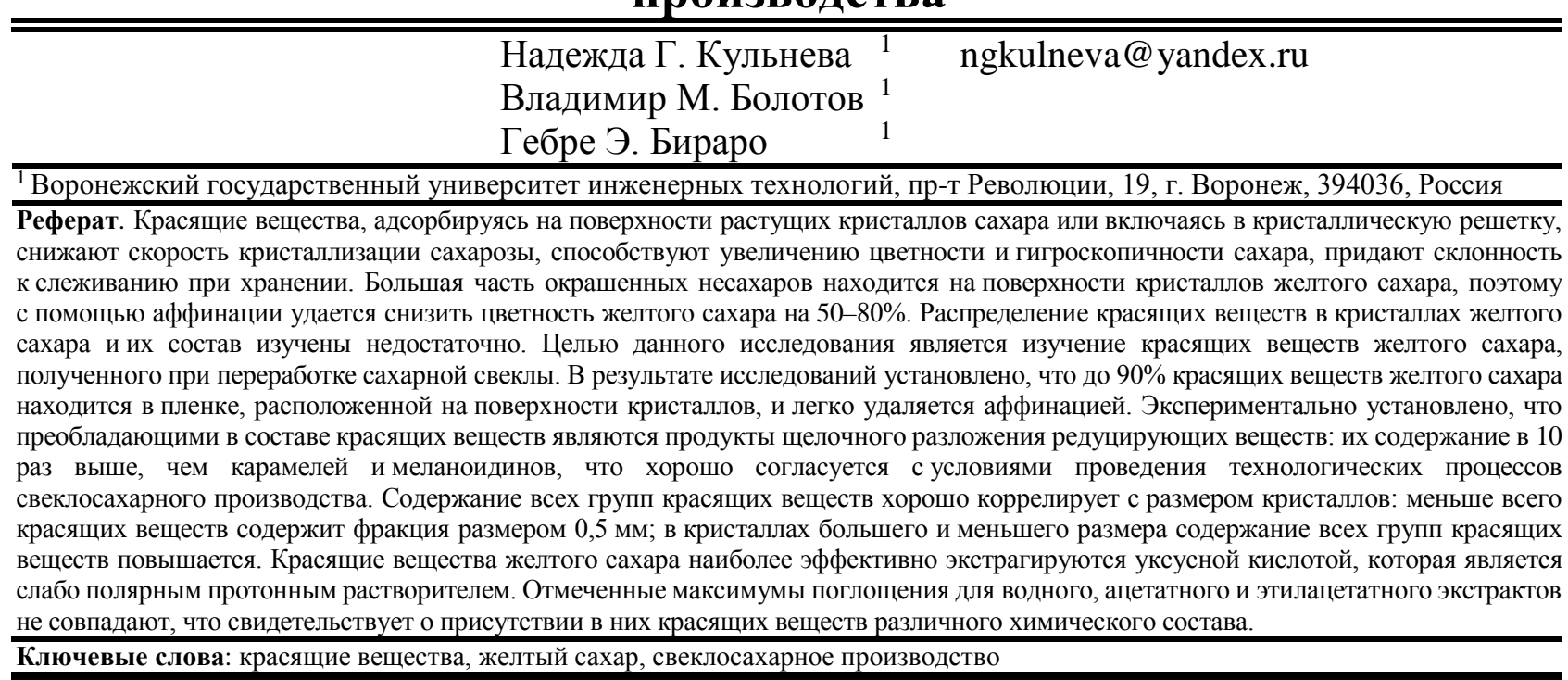

\title{
Analysis of yellow sugar coloring substances from sugar beet production
}

Nadezhda G. Kulneva 1
Vladimir M. Bolotov 1
Gebre E. Biraro

\section{Введение}

Известно, что красящие вещества, адсорбируясь на поверхности растущих кристаллов сахара или включаясь в кристаллическую решетку, снижают скорость кристаллизации сахарозы, способствуют увеличению цветности и гигроскопичности сахара, придают склонность к слеживанию при хранении его в силосах [1]. При добавлении в раствор 0,1-0,5\% смеси красящих веществ скорость кристаллизации сахарозы снижается

\section{Для цитирования}

Кульнева Н.Г., Болотов В.М., Бираро Г.Э. Анализ красящих веществ желтых сахаров свеклосахарного производства //Вестник ВГУИТ. 2018. Т. 80. № 2. С. 200-205. doi:10.20914/2310-1202-20182-200-205 на 5-16\% [2], а при добавлении 1-3\% продуктов карамелизации сахарозы - на 9-40\%.

О тормозящем действии красящих веществ и других несахаров на процесс кристаллизации сахарозы имеются сведения в работах $[3,4]$. Большая часть окрашенных несахаров находится на поверхности кристаллов желтого сахара, поэтому с помощью аффинации удается снизить цветность желтого сахара на 50-80\% и повысить чистоту на несколько единиц. Однако оставшиеся

For citation

Kulneva N.G., Bolotov V.M., Biraro G.E. Analysis of yellow sugar coloring substances from sugar beet production. Vestnik VGUIT [Proceedings of VSUET]. 2018. vol. 80. no. 2. pp. 200-205. (in Russian). doi:10.20914/2310-1202-2018-2-200-205 
в кристаллах несахара являются наиболее вредными, так как в их присутствии растут кристаллы неправильной формы, значительно замедляется скорость кристаллизации сахарозы.

Из-за отсутствия надежных аналитических методов распределение красящих веществ в кристаллах сахарозы изучено недостаточно, и не ясен характер включения несахаров в кристаллы - происходит это в результате окклюзии маточного раствора или синкристаллизации. Проведенные А.Р. Сапроновым и Р.А. Колчевой сравнения УФ-спектров полученных при растворении кристаллов фракций установили, что они не идентичны по наклону кривых и интенсивности полос поглощения спектрам несахаров, расположенных в пленке маточного раствора [5]. Это свидетельствует о физикохимическом различии несахаров в массе кристалла и на его поверхности.

Цель исследования - изучение красящих веществ желтого сахара, полученного при переработке сахарной свеклы. Эти красящие вещества до настоящего времени не были изучены, что объясняется сложностью их выделения в чистом виде. Сведения о природе, составе и свойствах красящих веществ необходимы для разработки мероприятий, направленных на снижение цветности сахара.

\section{Материалы и методы}

Исходным материалом для исследования служил желтый сахар, отобранный на Лискинском сахарном заводе. Образцы данного желтого сахара рассеяли на стандартном наборе сит для определения фракционного состава сахара, установили массовую долю и цветность каждой фракции (таблица 1).

Таблица 1.

Фракционный состав желтого сахара III кристаллизации

Table 1.

Fractional composition of yellow sugar III crystallization

\begin{tabular}{|c|c|c|c|c|c|c|c|}
\hline $\begin{array}{c}\text { Размер фракции, } \\
\text { мм } \\
\begin{array}{c}\text { Fractional size, } \\
\text { mm }\end{array}\end{array}$ & $<0,10$ & 0,10 & 0,15 & 0,50 & 0,60 & 0,75 & 1,20 \\
\hline $\begin{array}{c}\text { Массовая доля } \\
\text { фракции,\% } \\
\text { Маss fraction, \% }\end{array}$ & 1,31 & 2,42 & 62,67 & 14,00 & 7,95 & 5,80 & 5,85 \\
\hline
\end{tabular}

Методика проведения экспериментов заключается в следующем. Кристаллы желтого сахара III продукта помещали в насыщенный спиртово-сахарный раствор, перемешивали в течение 3 мин (аффинировали). Раствор после аффинации отбирали для анализа, а к оставшимся кристаллам вновь добавляли насыщенный раствор и опыт повторяли. Аффинацию кристаллов желтого сахара III продукта повторяли до возможно полной замены пленки межкристального раствора на поверхности кристаллов пленкой раствора сахарозы, о чем судили по уменьшению эффекта аффинации. Сравнивая цветность растворов исходных кристаллов желтого сахара и растворов после аффинации, определяли, сколько красящих веществ находилось на поверхности кристаллов и было удалено аффинацией, а сколько находится внутри.

Цветность исследуемых продуктов определяли как оптическую плотность их растворов концентрацией 15-20\% сухих веществ, отнесенную к 100 частям сухих веществ и толщине слоя раствора в кювете, равной $1 \mathrm{~cm}$, на фотоэлектроколориметре КФК-3 при длине волны 590 нм.

\section{Результаты и обсуждение}

Полученные данные позволяют сделать вывод, что большая часть красящих веществ желтого сахара (70-90\%) находится на поверхности кристаллов и легко удаляется аффинацией. Уже при первой обработке удаляется 42,5-43\% красящих веществ, при второй $12-16 \%$, при третьей - 20-34\%. Последующие обработки дают небольшое снижение цветности, после 10-й аффинации цветность межкристального раствора приближается к цветности раствора, используемого для аффинации (рисунок 1). Кристаллы сахара, оставшиеся после аффинации, содержат примерно 5-10\% красящих веществ от исходного их количества.

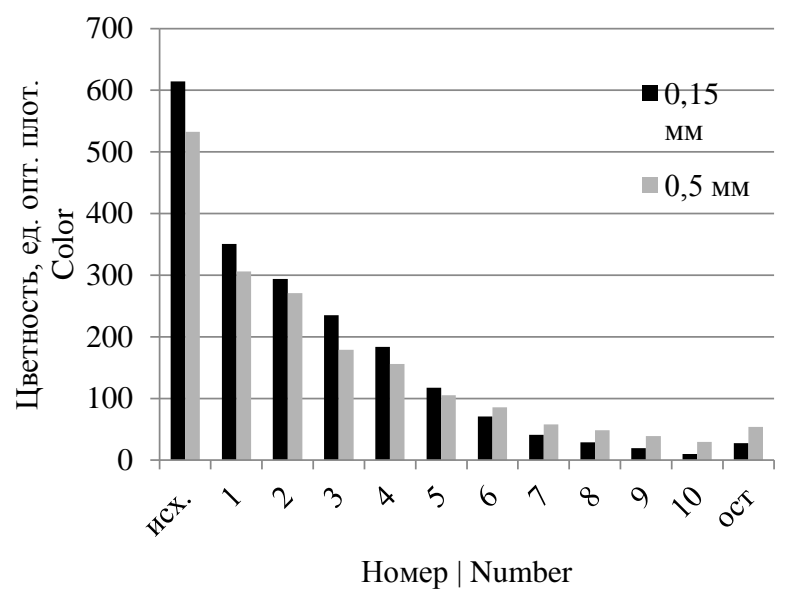

Рисунок 1. Результаты аффинации различных фракций желтого сахара насыщенным водноспиртовым раствором сахарозы

Figure1. The results of the affination of different fractions of yellow sugar by saturated aqueous alcohol solution of sucrose 


\section{Becmнuк BTYYTTI/Proceedings of VSUET, TII. 80, № 2, 2018}

Из приведенных данных видно, что красящие вещества в самом кристалле распределены по всей его массе. Причем, чем меньше размер кристаллов, тем выше эффект аффинации. Это дает основание предположить, что основную роль при включении красящих веществ в кристаллы III продукта играет окклюзия, т. е. механическое включение межкристального раствора в кристалл.

Для идентификации красящих веществ использовали методику, предложенную А.Р. Сапроновым, Р.А. Колчевой [5]. На УФ-спектрах красящих веществ сравнением коэффициентов поглощения при одной длине волны определяли характерные длины волн, при которых наблюдается максимальное светопоглощение вещества и наименьшее влияние других компонентов. Спектр поглощения продуктов щелочного распада редуцирующих сахаров при длине волны 250 нм, карамелана при длине волны 282 нм; меланоидинов при длине волны 300 нм.
Определив коэффициенты светопоглощения раствора желтого сахара, содержащего различные красящие вещества, при этих длинах волн соответственно $\mathrm{D}_{1}, \mathrm{D}_{2}, \mathrm{D}_{3}$, рассчитывали содержание красящих веществ по эмпирическим уравнениям:

$$
\begin{gathered}
X=\frac{79 D_{1}+33 D_{2}-105 D_{3}}{400}, \\
Y=\frac{-29 D_{1}+72 D_{2}-43 D_{3}}{400}, \\
Z=\frac{-5 D_{1}-23 D_{2}+50 D_{3}}{400},
\end{gathered}
$$

где: $X$ - концентрация продуктов щелочного распада редуцирующих сахаров, $\Gamma /$ дм $^{3} ; Y-$ концентрация карамелана, г/дм ${ }^{3} ; Z$ - концентрация меланоидинов, г/дм ${ }^{3}$ (таблица 2).

Таблица 2.

Содержание отдельных групп красящих веществ во фракциях желтого сахара III кристаллизации

Table 2.

The content of individual groups of coloring substances in the fractions of yellow sugar III crystallization

\begin{tabular}{|c|c|c|c|}
\hline \multirow{2}{*}{$\begin{array}{c}\text { Продукт } \\
\text { Product }\end{array}$} & \multicolumn{3}{|c|}{$\begin{array}{c}\text { Содержание красящих веществ, дм } \\
\text { The content of coloring substances }\end{array}$} \\
\cline { 2 - 4 } & $\begin{array}{c}\text { продукты щелочного pacпада } \\
\text { products of alkaline decomposition }\end{array}$ & $\begin{array}{c}\text { карамелан } \\
\text { caramelan }\end{array}$ & $\begin{array}{c}\text { меланоидины } \\
\text { melanoidins }\end{array}$ \\
\hline Желтый caxap / Yellow sugar & 3,1676 & 0,3680 & 0,2950 \\
\hline Фракция (Fraction) 0,75 мм & 3,0172 & 0,2817 & 0,2779 \\
\hline Фракция (Fraction) 0,5 мм & 2,8132 & 0,2805 & 0,2427 \\
\hline Фракция (Fraction) 0,15 мм & 3,3016 & 0,2948 & 0,2897 \\
\hline
\end{tabular}

Экспериментально установлено, что содержание всех групп красящих веществ хорошо коррелирует с размером кристаллов: меньше всего красящих веществ содержит фракция размером 0,5 мм; в кристаллах большего и меньшего размера содержание всех групп красящих веществ повышается. Преобладающими являются продукты щелочного разложения редуцирующих веществ: их содержание в 10 раз выше, чем карамелей и меланоидинов, что хорошо согласуется с условиями проведения технологических процессов свеклосахарного производства.

В технических сахарных растворах параллельно протекают различные реакции распада, конденсации, полимеризации, в результате которых в зависимости от химического состава исходного сырья и технологического режима образуется смесь красящих веществ, изучению которых в литературе уделяется значительное внимание [6, 7].

Один из труднейших этапов в изучении красящих веществ сахарного производства выделение их в чистом виде без нарушения молекулярной структуры, так как они очень чувствительны к кислотам, щелочам, высокой температуре и др.
Более мягкий способ извлечения красящих веществ - их адсорбция, но этот метод пригоден только тогда, когда сохраняется обратимость связи адсорбента и адсорбтива. Такие адсорбенты, как активный уголь, окись алюминия, целлюлоза и другие, обладают высокой энергией связи адсорбента и адсорбтива, в результате чего значительная часть красящих веществ сорбируется необратимо. Поэтому приходится применять агрессивные экстрагирующие жидкости.

Для экстракции красящих веществ использовали растворители с различной степенью полярности: дистиллированную воду, уксусноэтиловый эфир, уксусную кислоту, н-гексан, 1-бутанол, изопропанол, н-пропанол. Окрашенные экстракты были получены только при использовании воды, уксусной кислоты и уксусноэтилового эфира (рисунки 2-4). Переход веществ из твердой фазы в растворитель повышает показатель преломления раствора, что установлено экспериментально (таблица 3). Использование остальных растворителей не дало видимого результата при обработке мелкокристаллического желтого сахара. 
Показатели преломления растворителей

Таблица и их экстрактов

Table 3 .

Refractive indices of solvents and their extracts

\begin{tabular}{|c|c|c|}
\hline \multirow{2}{*}{$\begin{array}{c}\text { Растворитель } \\
\text { Delute }\end{array}$} & \multicolumn{2}{|c|}{ Показатель преломления } \\
\cline { 2 - 3 } & $\begin{array}{c}\text { растворителя } \\
\text { delute }\end{array}$ & $\begin{array}{c}\text { экстракта } \\
\text { solute }\end{array}$ \\
\hline $\begin{array}{c}\text { Дистиллированная вода } \\
\text { Distilled water }\end{array}$ & 1,333 & 1,413 \\
\hline $\begin{array}{c}\text { Уксусно-этиловый эфир } \\
\text { Vinegar-ethyl ether }\end{array}$ & 1,371 & 1,372 \\
\hline $\begin{array}{c}\text { Уксусная кислота } \\
\text { Асеtic асіd }\end{array}$ & 1,370 & 1,378 \\
\hline
\end{tabular}

Очевидно, эффективность экстракции красящих веществ обусловлена не только величиной дипольного момента, но и его диэлектрической проницаемостью.

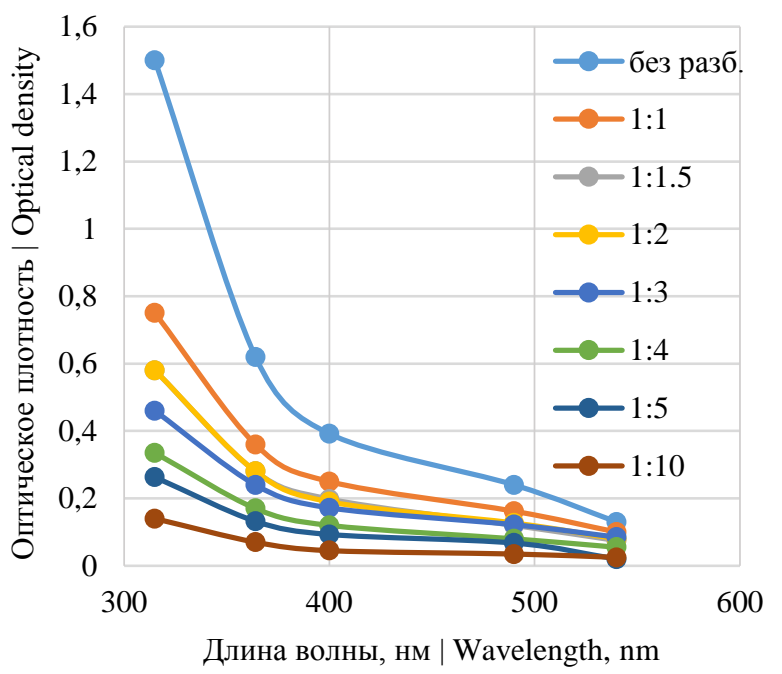

Рисунок 2. Спектры поглощения красящих веществ, экстрагированных дистиллированной водой, в зависимости от длины волны и степени разбавления

Figure 2. Absorption spectra of dyes extracted with distilled water, depending on the wavelength and degree of dilution

Экстракция водой приводит не только к извлечению красящих веществ, но и растворению сахарозы. Полученные растворы имеют достаточно низкую оптическую плотность в видимом диапазоне (до 0,4), однако значения существенно повышаются при переходе в ультрафиолетовую область (ниже 400 нм). Такая же закономерность наблюдается для экстрактов уксусно-этилового эфира. В отсутствии растворенной сахарозы оптическая плотность данных экстрактов в видимой области спектра ниже 0,1 и существенно повышается при переходе в ультрафиолетовый диапазон.

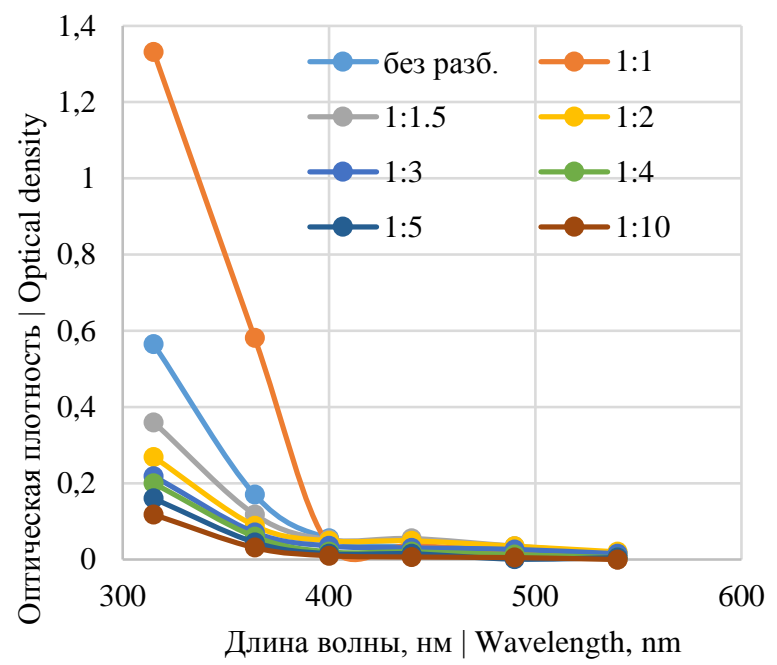

Рисунок 3. Спектры поглощения красящих веществ, экстрагированных уксусно-этиловым эфиром

Figure 3. Absorption spectra of dyes extracted with acetic ethyl ether

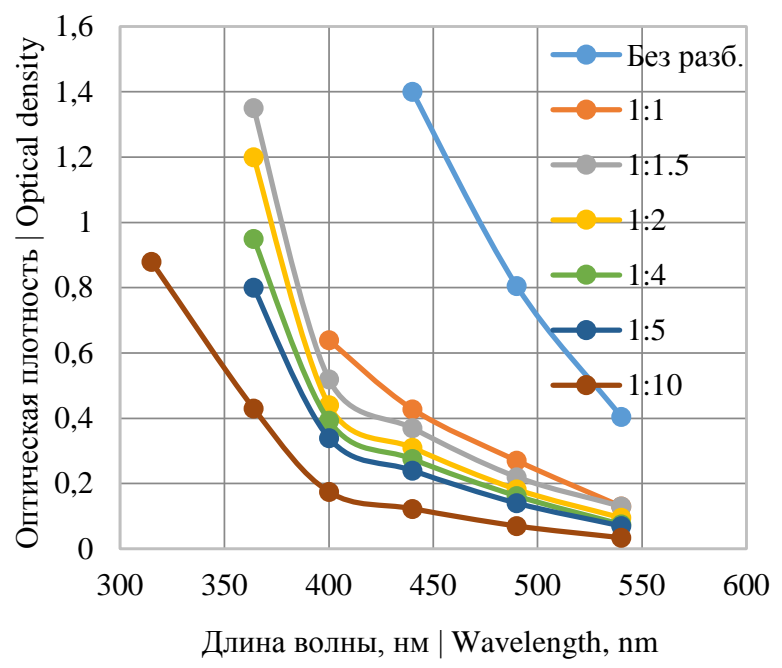

Рисунок 4. Спектры поглощения красящих веществ, экстрагированных уксусной кислотой, в зависимости от длины волны и степени разбавления

Figure 4. Absorption spectra of dyes extracted with acetic acid, depending on the wavelength and degree of dilution

Использование уксусной кислоты позволяет получить высоко окрашенные экстракты, оптическая плотность которых даже при длине волны 400-550 нм превышает границы диапазона измерений используемого прибора.

Для выяснения видов красящих веществ в кристаллах желтого сахара на спектрофотометре UV-1240 mini (Shimadzu) в ультрафиолетовой области спектра определяли поглощение света каждым экстрактом при 10-кратном разбавлении (рисунок 5). 


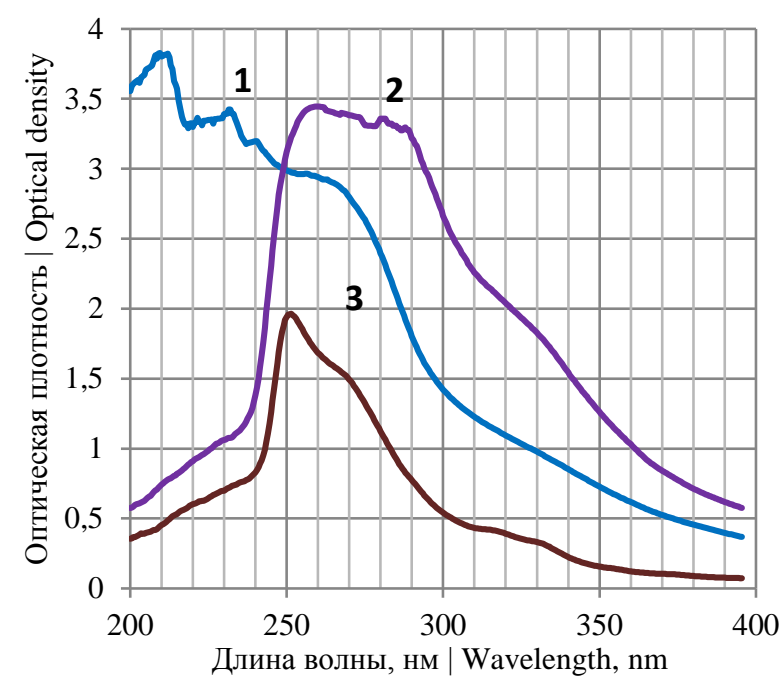

Рисунок 5. Спектр поглощения красящих веществ, экстрагированных дистиллированной водой (1), уксусной кислотой (2) и уксусно-этиловым эфиром (3) Figure 5. Absorption spectrum of dyes extracted with distilled water (1), acetic acid (2) and acetic ethyl ether (3)

Водный экстракт имеет несколько максимумов поглощения при длинах волны 210, 232 и 240 нм, что свидетельствует о сложном составе компонентов, входящих в его состав. Можно предположить, что максимум поглощения при длине волны 210 нм обусловлен присутствием карбонильной группы, а также $\alpha, \beta$-непредельных карбоновых кислот или их производных; при длине волны 232-240 нм - $\alpha, \beta-$ ненасыщенными оксосоединениями; при длине волны 250-280сопряженными $\pi$-связями.

Уксусный экстракт показывает широкую полосу поглощения в диапазоне 250-290 нм со слабо выраженным максимумом при длине волны 262 нм, что может быть обусловлено присутствием красящих веществ не идентифицированного строения с гидроксильными группами

\section{ЛИТЕРАТУРА}

1 Сапронов А.Р., Сапронова Л.А., Ермолаев С.В. Технология сахарного производства. СПб.: ИД «Профессия», 2015. 296 с.

2 Reinefeld E., Mussawi-Barab M.H. Uber Melassefarbstoffe // Zucker. 1963. № 12. P. 322-332.

3 Bharose R., Verma S.K. Cane Sugar Colour and Colourants // The Indian Journal of Basic and Applied Research. 2016. V. 1. № 3. P. 55-61.

4 Кульнева Н.Г. и др. Исследование цветовых характеристик полупродуктов сахарного производства // Вестник ВГУИТ. 2017. № 1. С. 300-304.

5 Колчева Р.А., Сапронов А.Р. Красящие вещества и их влияние на качество сахара. М.: Пищевая промышленность, 1975. 346 с.

6 Тарасова И.А. Исследования сахаросодержащих красящих растворов методом дифференциально сканирующей калориметрии // Сахар. 2017. № 3. C. 48-49. и электродонорными атомами (например, азота), образующими сольваты с карбоксильной группой уксусной кислоты, а также предельными альдегидами или кетонами.

Оптическая плотность экстракта уксусноэтилового эфира в этом диапазоне в 2 раза ниже, отмечается максимум поглощения при длине волны 253 нм. Вероятно, это поглощение связано с присутствием $\alpha, \beta-$ ненасыщенных оксосоединений. Небольшой максимум при длине волны 270 нм обусловлен карбонильными соединениями [7-10].

Экспериментальные исследования показывают, что наличие в органических молекулах кратных связей или функциональных групп, имеющих неподеленные пары электронов, связано с появлением поглощения в области 200-800 нм. Длина волны, на которой происходит поглощение света веществом, зависит от наличия в нем определенных двойных связей и от их числа [11]. Группы атомов, вызывающие поглощение в УФ и видимой областях спектра, содержат кратные связи или атом со свободной парой электронов $(\mathrm{C}=\mathrm{O}, \mathrm{NO}, \mathrm{N}=\mathrm{N})$.

\section{Заключение}

В результате исследований установлено, что до 90\% красящих веществ желтого сахара находится в пленке, расположенной на поверхности кристаллов, и легко удаляется аффинацией. Красящие вещества желтого сахара наиболее эффективно экстрагируются уксусной кислотой, которая является слабо полярным протонным растворителем. Отмеченные максимумы поглощения для водного, ацетатного и этил-ацетатного экстрактов не совпадают, что свидетельствует о присутствии в них красящих веществ различного химического состава.

7 Скобун А.С., Белодедова Ж.В. Органическая химия. Качественный анализ биоорганических соединений: Лабораторный практикум. СПб: НИУ ИТМО, 2014. 57 c. URL: https://e.lanbook.com/book / 70958.

8 Alcázar-Alay S.C. et al. Study of an extraction process as the pretreatment step for sugar production from acid hydrolysis //Food and Public Health. 2015. V. 5. №. 2. P. 47-55.

9 Vasylyshyna E. Influence of freezing and storing cherry fruit on its nutritional value // Acta Scientiarum Polonorum Technologia Alimentaria. 2016. V. 15. №. 2. P. 145-150.

10 Maravić N. et al. Physico-Chemical Characteristics of White Sugar Fractions Separated by Crystal Sizes // Analecta Technica Szegedinensia. 2016. V. 10. №. 2. P. 42-48.

11 Hubbermann E.M. Coloring of Low-Moisture and Gelatinized Food Products // Handbook on Natural Pigments in Food and Beverages. 2016. P. 179-196. 


\section{REFERENCES}

1 Sapronov A.R., Sapronova L.A., Ermolaev V.S. Tekhnologiya sakharnogo proizvodstva [Technology of sugar production] Saint-Petersburg, ID "Profession", 2015. 296 p. (in Russian)

2 Reinefeld E., Mussawi-Barab M.H. Uber Melassefarbstoffe. Zucker. 1963. no. 12. pp. 322-332.

3 Bharose R., Verma S.K. Cane Sugar Colour and Colourants. The Indian Journal of Basic and Applied Research. 2016. vol. 1. no. 3. pp. 55-61.

4 Kulneva N.G. et al. The study of color characteristics of semi-products of sugar production. Vestnik VGUIT [Proceedings of VSUET] 2017. no. 1. pp. 300-304. (in Russian)

5 Kolcheva R.A., Sapronov A.R. Krasyashchie veshchestva I ikh vliyanie [Dyes and their impact on the quality of the sugar] Moscow, Food industry, 1975. 346 p. (in Russian)

\section{СВЕДЕНИЯ ОБ АВТОРАХ}

Надежда Г. Кульнева д.т.н., профессор, кафедра технологии бродильных и сахаристых производств, Воронежский государственный университет инженерных технологий, пр-т Революции, 19, г. Воронеж, 394036, Россия, ngkulneva@yandex.ru

Владимир М. Болотов д.х.н., профессор, кафедра химии и химической технологии органических соединений и переработки полимеров, Воронежский государственный университет инженерных технологий, пр-т Революции, 19, г. Воронеж, 394036, Россия

Гебре Э. Бираро аспирант, кафедра технологии бродильных и сахаристых производств, Воронежский государственный университет инженерных технологий, пр-т Революции, 19, г. Воронеж, 394036, Россия

\section{КРИТЕРИЙ АВТОРСТВА}

Надежда Г. Кульнева предложила методику проведения эксперимента

Владимир М. Болотов консультация в ходе исследования Гебре Э. Бираро написал рукопись, корректировал её до подачи в редакцию и несёт ответственность за плагиат

КОНФЛИКТ ИНТЕРЕСОВ

Авторы заявляют об отсутствии конфликта интересов.

ПОСТУПИЛА 12.04.2018

ПРИНЯТА В ПЕЧАТЬ 16.05.2018
6 Tarasova I.A. Studies of sugar-containing coloring solutions by differential scanning calorimetry. Sakhar [Sugar] 2017. no. 3. pp. 48-49. (in Russian)

7 Skobun A.S., Belodedova J.V. Organicheskaya khimiya. Kachestvannyi analiz [Organic chemistry. Qualitative analysis of Bioorganic compounds: Laboratory workshop] Staint-Petersburg, ITMO, 2014. 57 p. Available at: https://e.lanbook.com/book / 70958 Oh.

8 Alcázar-Alay S.C. et al. Study of an extraction process as the pretreatment step for sugar production from acid hydrolysis. Food and Public Health. 2015. vol. 5. no. 2. pp. 47-55.

9 Vasylyshyna E. Influence of freezing and storing cherry fruit on its nutritional value. Acta Scientiarum Polonorum Technologia Alimentaria. 2016. vol. 15. no. 2. pp. 145-150.

10 Maravić N. et al. Physico-Chemical Characteristics of White Sugar Fractions Separated by Crystal Sizes. Analecta Technica Szegedinensia. 2016. vol. 10. no. 2. pp. 42-48.

11 Hubbermann E.M. Coloring of Low-Moisture and Gelatinized Food Products. Handbook on Natural Pigments in Food and Beverages. 2016. pp. 179-196.

\section{INFORMATION ABOUT AUTHORS}

Nadezhda G. Kulneva Dr. Sci. (Engin.), professor, technologies of fermentation and sugar production department, Voronezh state university of engineering technologies, Revolution Av., 19 Voronezh, 394036, Russia, ngkulneva@yandex.ru

Vladimir M. Bolotov Dr. Sci. (Chem.), professor, chemistry and chemical technology of organic compounds and polymer processing department, Voronezh state university of engineering technologies, Revolution Av., 19 Voronezh, 394036, Russia

Gebre E. Biraro graduate student, technologies of fermentation and sugar production department, Voronezh state university of engineering technologies, Revolution Av., 19 Voronezh, 394036, Russia

\section{CONTRIBUTION}

Nadezhda G. Kulneva proposed a scheme of the experiment

Vladimir M. Bolotov consultation during the study

Gebre E. Biraro wrote the manuscript, correct it before filing in editing and is responsible for plagiarism

CONFLICT OF INTEREST

The authors declare no conflict of interest.

RECEIVED 4.12.2018

ACCEPTED 5.16.2018 